\title{
Similarity Study on Snowdrift Wind Tunnel Test
}

\author{
Weihua Wang ${ }^{1,2}$, Haili Liao ${ }^{1}$, Mingshui Li ${ }^{1}$, Hanjie Huang ${ }^{2}$ \\ ${ }^{1}$ School of Civil Engineering, Southwest Jiaotong University, Chengdu, China \\ ${ }^{2}$ China Aerodynamics Research and Development Center, Mianyang, China \\ Email: wwhbluesun@sina.cn
}

Received July 2013

\begin{abstract}
The model for snowdrift wind tunnel test needs to be similar with the prototype. Based on detailed analysis in aspects of geometry, kinematics and dynamics, the major similarity parameters that need to be satisfied are gained. The contradiction between the Reynolds number and Froude number as well as the problem of time scale is introduced, and the selections of the model parameters are specified. Lastly, an example of snowdrift wind tunnel test by adoption of quartz sand as the model of snow grains is presented. The flow field and the snow distributions on a typical stepped roof were investigated. The results show that the flow filed characters are in good agreement with the field observations, and the stepped roof snow depth distributions are basically consistent with the observation results.
\end{abstract}

Keywords: Similarity Parameters; Wind Tunnel Test; Snowdrift; Roof

\section{Introduction}

Snowdrift forms the unbalanced distribution on roof under the wind actions, leading to excessively great snow load on local roof, eventually resulting in collapse of the building [1]. Such incidents of structure damage by snow load are not rarely seen. Especially in recent years, with changes of global climate, wind and snow disasters become more and more frequent, exerting significantly negative impact on people's daily life, thus snow disaster prediction and prevention has drawn increasingly more attentions.

Wind-induced snow drifts include creep, saltation and suspension, as shown in Figure 1. Wind-induced snow drift research is mainly conducted through field observation, wind tunnel (or water flume) test and numerical simulation, with each having their own advantages and drawbacks. Wind tunnel test, due to its accessibility for easy control and systematic study, is regarded as an important research method. Snowdrift wind tunnel simulation needs to keep similarities between the model and prototype in geometry, kinematics, and dynamics.

\section{Geometric Similarities}

Geometric similarity requires equivalence of the ratios of geometric dimensions to characteristic dimensions between the model and prototype,

$$
(l / L)_{\mathrm{m}}=(l / L)_{\mathrm{p}}
$$

where $l$ is linear dimension, $L$ is a characteristic length, and subscripts $\mathrm{m}$ and $\mathrm{p}$ refer to model and prototype respectively.

According to the similarity criterion, all the geometric dimensions in the physical model shall meet Equation (1), including the terrain and surrounding buildings in the test domain. The geometric dimensions of snow grains, however, would introduce difficulties in simulations. For example, for simulation of medium-sized snow grains in a diameter of $0.5 \mathrm{~mm}$, in case of the geometric scale being $1 / 50$, the diameter of the model snow grain needs to be $10 \mu \mathrm{m}$. Obviously, there is difficulty in operations on such small particles in the lab; and the excessively small size of particles would lead to unduly great threshold velocity. Fortunately, abandonment of this parameter would not bring in significant impact [3]. The diameters of snow grain model for wind tunnel test generally can select a range of $0.05-0.2 \mathrm{~mm}$.

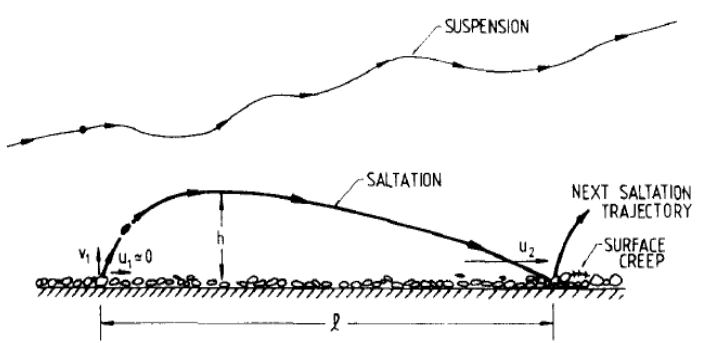

Figure 1. Sketch of saltation, suspension and creep trajectories [2]. 


\section{Kinematic Similarities}

Kinematic similarity requires equivalence of the ratios of flow speeds at various points between the model and prototype,

$$
(u / U)_{\mathrm{m}}=(u / U)_{\mathrm{p}}
$$

where $u$ is the flow speed and $U$ is the characteristic velocity.

Kinematic similarity implies the reproduction of the atmospheric turbulent structures. The flow field velocity profile at the atmospheric boundary layer conforms to the logarithmic law, with the incoming flow mainly simulated with Jensen number. Owen [4] pointed out that within the flow field having particle movement, saltation particles continuously absorbed energy from the air flow, leading to the decrease of flow speed, this was equivalent to increase the effective aerodynamic roughness-length $\left(z_{0}\right.$ ') of the field. The flow field velocity profile outside the saltation layer conforms to the following:

$$
u(z)=\frac{u_{*}}{\kappa} \ln \left(\frac{2 g z}{u^{2}}\right)+C
$$

where $u_{*}$ is the shear velocity, $k$ is the Von Karman constant, and $C$ is a constant.

Kinematic similarity implies that the restitute coefficients of the model and the prototype should be kept consistent. However, studies show that the restitute coefficient has no significant impact on the particle movement [5]. Therefore, this parameter is generally ignored in wind tunnel tests. Besides, the atmospheric turbulence intensity and turbulence length scale should also be similar in theory, but it can be relaxed in wind tunnel tests when the time average results are concerned.

\section{Dynamic Similarities}

Dynamic similarity is a very important and complicated condition for the simulation of physical models. Snowdrift is a gas-solid two-phase flow, with very complicated mutual coupling mechanism. Dimensional analysis showed that there are dozens of relevant parameters for simulation [6]. Clearly, it's impossible to satisfy all the parameters, but only the major parameters need to be taken into consideration. This section presents the derivation of the similarity parameters through the analysis of particle motion and transport mechanism.

\subsection{Equations of Motion}

Assuming snow particle is approximately spherical with a diameter of $d$, thus its motion Equation can be expressed as

$$
\frac{\pi}{6} \rho_{p} d^{3} \frac{d \mathbf{u}}{d t}=\frac{\pi}{6} \rho_{p} d^{3} \mathbf{g}-\frac{\pi}{8} C_{D} \rho d^{2}\left|\mathbf{u}_{r}\right| \mathbf{u}_{r}-\frac{\pi}{6} \rho d^{3} \mathbf{g}+\mathbf{R} \text { (4) }
$$

where $\rho$ is the fluid density, $\rho_{p}$ is the particle density, $C_{D}$ is the drag coefficient, $\mathbf{g}$ is the acceleration vector, $\mathbf{u}$ is the particle speed vector, and $\mathbf{u}_{\mathbf{r}}$ is the particle speed relative to fluid.

Gravity, drag and buoyancy are the most important forces for an aeolian grain than other forces. So the Equation (4) can reduce to

$$
\frac{d \mathbf{u}}{d t}=\left(1-\frac{\rho}{\rho_{p}}\right) \mathbf{g}-\frac{3}{4} \frac{\rho}{\rho_{p}} \frac{1}{d} C_{D}\left|\mathbf{u}_{r}\right| \mathbf{u}_{r}
$$

Assuming $\hat{\mathbf{u}}=\mathbf{u} / U ; \hat{t}=t / T$, where $T$ is a characterristic time, and $T=L / U$, thus nondimensional Equation (5) is

$$
\frac{d \hat{\mathbf{u}}}{d \hat{t}}=\frac{L \mathbf{g}}{U^{2}}\left(1-\frac{\rho}{\rho_{p}}\right)-\frac{3}{4} \frac{\rho}{\rho_{p}} \frac{L}{d} C_{D}\left|\hat{\mathbf{u}}_{r}\right| \mathbf{u}_{r}
$$

Assuming $\Pi_{1}=L g / U^{2}\left(1-\rho / \rho_{p}\right), \quad \Pi_{1}$ is the Froude number, $g$ is the gravity acceleration, and $\Pi_{2}=3 \rho L C_{D} / 4 \rho_{p} d$. Assuming $w_{f}$ is the terminal velocity of particle, then equilibrium of drag, gravitational force and buoyancy yields

$$
\frac{L g}{U^{2}}\left(1-\frac{\rho}{\rho_{p}}\right)=\frac{3}{4} \frac{\rho}{\rho_{p}} \frac{L}{d} C_{D}\left(\frac{w_{f}}{U}\right)^{2}
$$

and

$$
\Pi_{2}=\Pi_{1}\left(U / w_{f}\right)^{2}
$$

Defining nondimensional parameter $\Pi_{3}=U / w_{f}$, then $\Pi_{2}$ is the combination of $\Pi_{1}$ and $\Pi_{3}$.

\subsection{Mass Transport}

Wind-induced snow transport is mainly achieved by saltation. Saltation occurs within the lower layer about $2 \mathrm{~cm}$ high above the surface [7]. Provided that a typical saltation particle ascending horizontal speed is 0 , the average horizontal landing speed is $u_{2}$, the average saltation length is $l$ (as shown in Figure 1), and $Q(\mathrm{~kg} / \mathrm{m} / \mathrm{s})$ is the mass transport rate, then the shearing force of wind acting on the saltation transport is $\tau_{s}=Q u_{2} / l$. Assuming the total shearing force of wind is $\tau$, then the shearing force of wind acting on the surface bed is $\tau_{b}=\tau-\tau_{s}$. Owen [4] has suggested that the shearing force of wind acting on the bed should be kept on threshold level, i.e. $\tau_{b}=\tau_{t h}$. As if $\tau_{b}>\tau_{t h}$, more particles would be inspired to make motion, leading to $\tau_{s}$ increases and $\tau_{b}$ decreases; otherwise, if $\tau_{b}<\tau_{t h}$, more particles tend to cease motion, so $\tau_{s}$ decreases and $\tau_{b}$ increases. It looks like that there exists a self-balancing mechanism in mass transport.

So based on above analysis there is

$$
Q u_{2} / l=\tau-\tau_{t h}=\rho\left(u_{*}^{2}-u_{* t h}{ }^{2}\right)
$$

Provided the average ascending vertical velocity of 
particle is $v_{1}$, then there is $u_{2} / l=g / v_{1}$, and $v_{1}$ is proportional to friction velocity [8], i.e. $v_{1} \approx \alpha u_{*}$, where $\alpha$ is a coefficient. Substituting those relationships into Equation (9) yields

$$
\frac{Q g}{\rho u_{*}^{3}}=\alpha\left(1-\frac{u_{* t h}{ }^{2}}{u_{*}^{2}}\right)
$$

Equation (10) shows that nondimensional mass transport rate is related to the ratio of shear velocity and threshold shear velocity. Assuming $\Pi_{4}=u_{* t h} / u_{*}$, the parameter $\Pi_{4}$ can be replaced as $\Pi_{5}=U_{t h} / U$, where $U_{t h}$ is the threshold reference velocity.

In summary, the dynamic similarity parameters mainly include

$$
\begin{aligned}
& {\left[L g / U^{2}\left(1-\rho / \rho_{p}\right)\right]_{\mathrm{m}}=\left[L g / U^{2}\left(1-\rho / \rho_{p}\right)\right]_{\mathrm{p}}} \\
& \left(U / w_{f}\right)_{\mathrm{m}}=\left(U / w_{f}\right)_{\mathrm{p}} \\
& \left(U_{t h} / U\right)_{\mathrm{m}}=\left(U_{t h} / U\right)_{\mathrm{p}}
\end{aligned}
$$

\section{Reynolds Number and Time Scale}

\subsection{Reynolds Number}

Wind tunnel test model can be established according to the above rules, such as studied by Isymouv [9], Sant' Anna [10], O'rourke [11]. Kind [5] suggested that the Reynolds number should be taken into account and introduced the Reynolds number of roughness-height, i.e. $u_{*}^{3} /(2 g v)$, where $v$ is the fluid kinematic viscosity coefficient. The Reynolds number for natural snowdrift is about 50. In case that the geometry scale of the model is $1 / 100$, as per the relationship between the velocity and geometric dimension in Equation (11), the Reynolds number of roughness-height is 0.05 , far less than the lower limit of formation aerodynamic roughness flow. Therefore, Kind [5] has suggested the model should satisfy

$$
u_{*}^{3} / 2 g v \geq 30
$$

The Equation (14) implies that the friction speed of wind tunnel test should be above $0.2 \mathrm{~m} / \mathrm{s}$, but Kind has also noted that the requirement may be appropriately relaxed. With high wind velocity, Equation (11) would not be satisfied, hereby indicating the classic contradictions between the Reynolds number and the Froude number. Distortion of the Froude number results in that the saltation length of particles exceeds the required values. However, it's believed that as long as the geometry dimension of model is greater than the saltation length of particles, the result error would be not so significant [12]. The saltation length of particle is about 10 times of the saltation height, and the average saltation height of par- ticle is approximately $1.6 u * /(2 g)$ [8], then the dimension of the model should comply with the following

$$
8 u_{*}^{2} / g L \ll 1
$$

which can be satisfied readily in a usual wind tunnel test.

\subsection{Time Scale}

Abandonment of Froude number brings the uncertainty of time scale. Kind [2] has ignored the effect of Froude number, and suggested the time scale as

$$
t U / L \text { or } \rho t U / L \rho_{p}
$$

Anno [13] has adopted mass transport rate for reference. The time scale suggested by Anno [13] is generally deemed as reasonable, but the mass transport rate needs to be determined, which is difficult for the prototype. The expression for Anno' time scale is

$$
t Q / \rho_{s} L^{2}
$$

Iversen [6] introduced similar time scale parameters, but he didn't adopt mass transport rate explicitly, but a function of other variable, which need to be determined through test. One form of the time scales as suggested by Iversen [6] is

$$
\frac{\rho}{\rho_{p}} \frac{U^{2}}{g L}\left(1-\frac{U_{t h}}{U}\right) \frac{t U}{L}
$$

\section{Wind Tunnel Test}

In the present test, a geometric scale ratio of $1 / 40$ was used. For the snow grain model, the quartz sand with an average diameter of $0.2 \mathrm{~mm}$ in irregular shapes was adopted. The effect of angle of repose should also be taken into account in wind tunnel test. The angle of repose for natural snow grains can exceed $90^{\circ}$, which is hardly realized for a model particle in wind tunnel. However, the angle of repose is important only in the test involved simulation of steep shape; it generally ensures approximation as closely as possible [2].

The properties of model particles and the major similarity parameters are listed in Table $\mathbf{1}$. It can be seen that the $u_{*}{ }^{3} /(2 g v)$ and $u_{*} / u_{* t}$ of the model fall within the required range; while $w_{f} / u_{*}$ is 2 - 3 times larger than the prototype value, which is mainly because $w_{f}$ of the model particle is a little too large. The most significant difference is the Froude number (taking $u_{*}$ for reference) such that the model is two orders of magnitudes larger than the prototype, so the Froude number simulation is distorted.

A series of tests were carried out in XNJD-2 wind tunnel at Southwest Jiaotong University in China. The working section of the tunnel is $10 \mathrm{~m}$ in length, $1.3 \mathrm{~m}$ in width, and $1.5 \mathrm{~m}$ in height; the wind velocity can be 
Table 1. Particle properties and typical similitude parameters

\begin{tabular}{ccc}
\hline Parameters & Model values & Prototype values [3,5,14] \\
\hline Mean diameter $(\mathrm{mm})$ & 0.2 & $0.1-0.5$ \\
Density $\left(\mathrm{kg} / \mathrm{m}^{3}\right)$ & 2560 & $500-900$ \\
Angle of repose $\left(^{\circ}\right)$ & 31 & $>40$ \\
$u_{*_{t}}(\mathrm{~m} / \mathrm{s})$ & 0.149 & $0.118-0.28$ \\
$w_{f}(\mathrm{~m} / \mathrm{s})$ & 2.13 & $0.31-0.75$ \\
$u_{*_{t}}{ }^{3} /(2 g v)$ & 13.00 & $7.0-70.0$ \\
$u_{*} / u_{*_{t}}$ & $1.23-1.59$ & $0.66-7.93$ \\
$w_{f} / u_{*}$ & $8.987-11.768$ & $0.327-3.93$ \\
$u_{*}^{2} / L g$ & $0.0171-0.0287$ & $0.00043-0.00072$ \\
$w_{f} / u_{*_{t}}$ & 14.2 & $2.16-5$ \\
\hline
\end{tabular}

varied between 0 and $19 \mathrm{~m} / \mathrm{s}$. Before the wind tunnel test, a $3 \mathrm{~m}$-long quartz sand particle bed was paved in front of the model, with a thickness of $3 \mathrm{~cm}$. A $5 \mathrm{~m} \times 4 \mathrm{~m}$ collection box was laid below the wind tunnel exit to collect the particles flying out of the wind tunnel, which would be used for calculation of mass transport rate. Figure 2 presents a snapshot of the test.

The flow field was measured by the KANOMAX anemometer. Measurement of the wind velocity profiles included four nominal wind speeds: $4.5 \mathrm{~m} / \mathrm{s}, 5 \mathrm{~m} / \mathrm{s}, 5.5$ $\mathrm{m} / \mathrm{s}$ and $6 \mathrm{~m} / \mathrm{s}$, corresponding to $3.87 \mathrm{~m} / \mathrm{s}, 4.14 \mathrm{~m} / \mathrm{s}, 4.60$ $\mathrm{m} / \mathrm{s}$ and $4.99 \mathrm{~m} / \mathrm{s}$ for reference velocities respectively. The threshold wind velocity was observed as $U_{t h}=4.14$ $\mathrm{m} / \mathrm{s}$.

Figure 3 shows the measured velocity profiles. As shown in the figure, when $U>U_{t h}$, the aerodynamic roughness-length increases as the wind speed increases. The $u_{*}$ obtained by fitting the measurement data of wind velocities are $0.130,0.149,0.183$ and 0.211 respectively.

According to Equation (3), $z_{0}{ }^{\prime}$ is proportional to $u_{*}{ }^{2}$. Figure 4 shows the fitting result of velocities. The fitting relationship is $z_{0}{ }^{\prime} \approx 0.00316 u_{*}{ }^{2} /(2 g)$, and $\mathrm{R}^{2}=0.839$, so based on the field data [8] there is $z_{0}{ }^{\prime}{ }^{\prime} / z_{0}{ }^{\prime}{ }_{m} \approx 38$.

The Iversen's time scale $\left(t_{p} / t_{m}\right)$ is calculated as 113 . At the nominal wind speed of $5.5 \mathrm{~m} / \mathrm{s}$ the Anno's time scale is 153 .

Figure 5 shows the nondimensional roof snow depth distributions (Cs) for a typical stepped building model at different time intervals, wind speeds and directions. The figure also presents Tsuchiya's [15] field observation results for similar model in Hokkaido of Japan. It can be seen from the figure that the test results are basically consistent with the field observation.

\section{Conclusions}

Through the analysis in aspects of geometry, kinematics and dynamics, the major similarity parameters that need

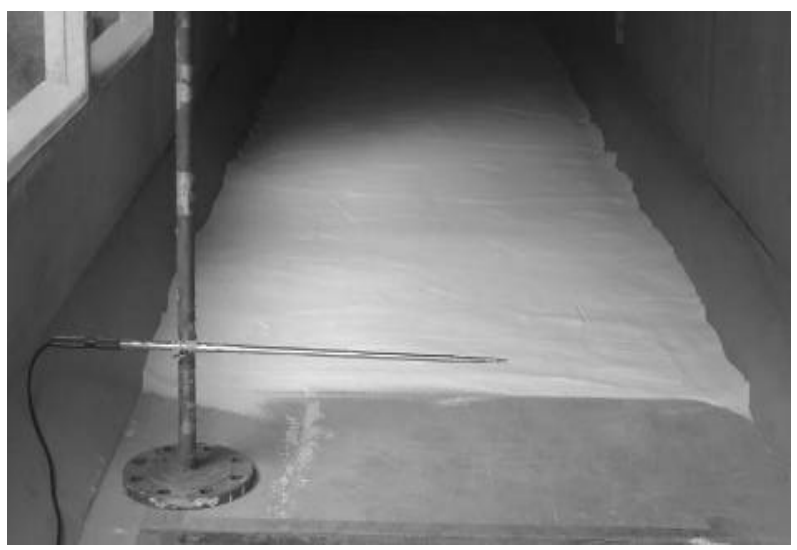

Figure 2. Snapshot of the test.

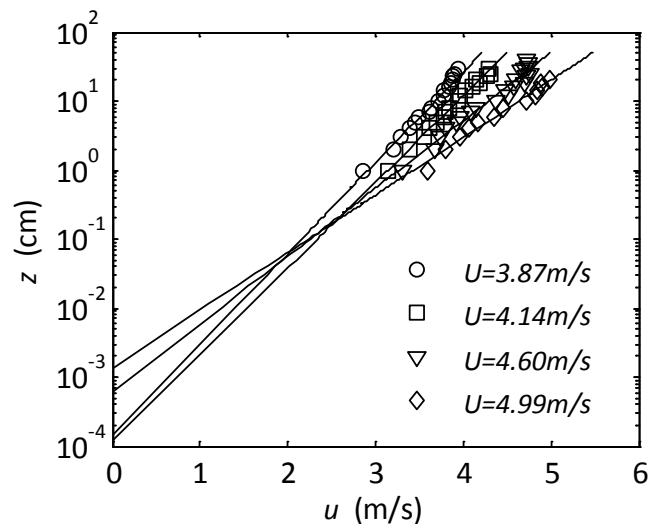

Figure 3. Velocity profiles.

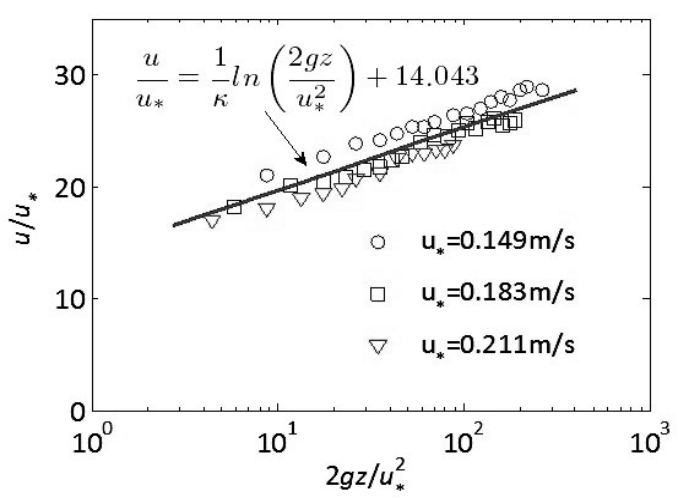

Figure 4. Fitting velocities.

to be satisfied for snowdrift wind tunnel test model are gained. As for the contradiction between the Reynolds number and Froude number, the existing wind tunnel tests generally place priorities on the Reynolds number above the Froude number, so the main similarity parameters that need to be satisfied for models include Equations (1), (2), (12), (13) and (14). As for Equation (11), it's generally ensured to minimize the difference of the model and the prototype. Other parameters also include angle of repose, restitute coefficient and time scale. 


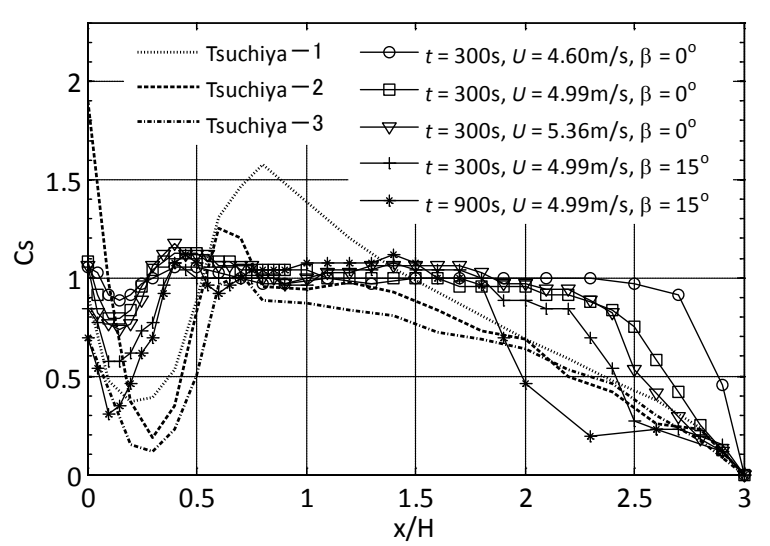

Figure 5. Roof snow depth distributions.

It should be pointed out that, the snowdrift-involved wind tunnel test is still in the development stage, thus there are many things that need to be improved, such as the impact of natural environment on the physical features (temperature, humidity, and sublimation, etc.) of snow grains in actuality, which has not been taken into consideration in wind tunnel simulations.

According to the similarity law, a wind tunnel test by adoption of quartz sand as the snow grain model was conducted. The flow field characters were measured and analyzed, and the roof snow distributions of a typical stepped building were investigated. The results show that, with the particle saltation, the velocity profiles outside the saltation layer agree well with the field observations; the stepped roof snow depth distributions are basically consistent with the observation results.

\section{Acknowledgements}

The project is supported by National Natural Science Foundation of China (Grant No. 41272832).

\section{REFERENCES}

[1] M. Holicky and M. Sykora, "Failures of Roofs under Snow Load Causes and Reliability Analysis,” Proceedings of the 5th Congress on Forensic Engineering, Washington DC, 11-14 November 2009, pp. 444-453. http://dx.doi.org/10.1061/41082(362)45

[2] R. J. Kind, "Mechanics of Aeolian Transport of Snow and Sand," Journal of Wind Engineering and Industrial Aerodynamics, Vol. 36, 1990, pp. 855-866. http://dx.doi.org/10.1016/0167-6105(90)90082-N

[3] D. J. Smedley, K. C. S. Kwok and D. H. Kim, "Snowdrifting Simulation around Davis Station Workshop, Antarctica,” Journal of Wind Engineering and Industrial
Aerodynamics, Vol. 50, pp. 153-162. http://dx.doi.org/10.1016/0167-6105(93)90070-5

[4] P. R. Owen, "Saltation of Uniform Grains in Air," Journal of Fluid Mechanics, Vol. 20, No. 2, 1964, pp. 225242. http://dx.doi.org/10.1017/S0022112064001173

[5] R. J. Kind, "Snowdrifting: A Review of Modeling Methods," Cold Regions Science and Technology, Vol. 12, No. 3, 1986, pp. 217-228. http://dx.doi.org/10.1016/0165-232X(86)90036-4

[6] J. D. Iversen, "Comparison of Wind-Tunnel Model and Full-Scale Snow Fence Drifts,” Journal of Wind Engineering and Industrial Aerodynamics, Vol. 8, 1981, pp. 231-249. http://dx.doi.org/10.1016/0167-6105(81)90023-4

[7] D. Kobayashi, "Studies of Snow Transport in Low-Level Drifting Snow,” The Institute of Low Temperature Science, 1972.

[8] J. W. Pomeroy and D. M. Gray, "Saltation of Snow," Water Resource Research, Vol. 36, No. 7, 1990, pp. 15831594. http://dx.doi.org/10.1029/WR026i007p01583

[9] N. Isyumov and M. Mikitiuk, "Wind Tunnel Model Tests of Snow Drifting on a Two-Level Flat Roof," Journal of Wind Engineering and Industrial Aerodynamics, Vol. 36, No. 2, 1990, pp. 893-904. http://dx.doi.org/10.1016/0167-6105(90)90086-R

[10] F. D. M. Sant'Anna and D. A. Taylor, "Snow Drifts on Flat Roofs: Wind Tunnel Tests and Field Measurements," Journal of Wind Engineering and Industrial Aerodynamics, Vol. 34, No. 3, 1990, pp. 223-250. http://dx.doi.org/10.1016/0167-6105(90)90154-5

[11] M. O’Rourke, A. Degaetano and J. D. Tokarczyk, "Snow Drifting Transport Rates from Water Flume Simulation,” Journal of Wind Engineering and Industrial Aerodynamics, Vol. 92, 2004, pp. 1245-1264. http://dx.doi.org/10.1016/j.jweia.2004.08.002

[12] J. H. Lever and R. Haehnel, "Scaling Snowdrift Development Rate,” Hydrological Processes, Vol. 9, 1995, pp. 935-946. http://dx.doi.org/10.1002/hyp.3360090809

[13] Y. Anno, "Requirements for Modeling of a Snowdrift," Cold Regions Science and Technology, Vol. 8, No. 3, 1984, pp. 241-252. http://dx.doi.org/10.1016/0165-232X(84)90055-7

[14] J. H. M. Beyers and T. M. Harms, "Outdoors Modelling of Snowdrift at SANAE IV Research Station, Antarctica,” Journal of Wind Engineering and Industrial Aerodynamics, Vol. 91, 2003, pp. 551-569. http://dx.doi.org/10.1016/S0167-6105(02)00409-9

[15] M. Tsuchiya, T. Tomabechi, T. Hongoa, et al., "Wind Effects on Snowdrift on Stepped Flat Roofs," Journal of Wind Engineering and Industrial Aerodynamics, Vol. 90, 2002, pp. 1881-1892. http://dx.doi.org/10.1016/S0167-6105(02)00295-7 